\title{
Editorial
}

\section{The First Annual Meeting of the Brazilian Institute of Neuropsychology and Behavior (IBNeC) in conjunction with the Second Forum on the Neurobiology of Stress}

\author{
Izabel Hazin $^{1}$, Lisiane Bizarro ${ }^{2}$ and Rosa Maria Martins de Almeida ${ }^{2}$ \\ 1 - Universidade Federal do Rio Grande do Norte, Natal, RN, Brazil \\ 2 - Universidade Federal do Rio Grande do Sul, Porto Alegre, RS, Brazil
}

The gap between psychology and neuroscience is widening more than ever. Different scientific associations in Brazil separately promote psychology, neuroscience, and neuropsychology. Nevertheless, the relationship among these fields endorses interdisciplinary and translational research, the goal of which is to approach basic-to-clinical research and vice-versa for a better understanding of emotion, behavior, and psychological processes and their alterations. Within this context, the Brazilian Institute of Neuropsychology and Behavior (Instituto Brasileiro de Neuropsicologia e Comportamento [IBNeC]) was founded on October 22,2009 . The IBNeC was an initiative of a group of Brazilian psychologists with an educational background in neuropsychology and behavioral neuroscience.

The $\mathrm{IBNeC}$ is a scientific society that brings together students, professors, and researchers who share a common interest in the relationship between brain and behavior. This is a multidisciplinary enterprise that seeks to integrate the knowledge produced by clinical and experimental research within the wide range of the fields of psychology and neuroscience. Creating its own identity, IBNeC contributes to the academic and professional growth of neuropsychology and behavioral neuroscience in Brazil, thus improving the impact of neuroscientific knowledge in psychological education. On September 23-25, 2010, IBNeC held its First National Meeting in conjunction with the Second

Izabel Hazin, Psychology Department, Universidade Federal do Rio Grande do Norte, Natal, RN, Brazil. Lisiane Bizarro and Rosa Maria Martins de Almeida, Graduate Program in Psychology, Institute of Psychology, Universidade Federal do Rio Grande do Sul. Correspondence regarding this editorial should be directed to: Izabel Hazin, Psychology Department Universidade Federal do Rio Grande do Norte, CCHLA, Av. Senador Salgado Filho, s/n, Lagoa Nova, Natal, RN, Brazil, CEP 59078-000. E-mail: izabel.hazin@gmail.com
Forum on the Neurobiology of Stress (see Brandão, 2010, for a special section on the first forum sponsored by the Institute of Neuroscience and Behavior).

More than 400 participants met in Rio de Janeiro for this landmark meeting of psychology and neuroscience. The program consisted of 16 lectures, 10 seminars, three clinical meetings, and two minicourses, in addition to poster sessions on subjects that ranged from the study of clinical cases to basic research. Two awards for distinguished contributions to research and teaching in psychology and neuroscience were given to Prof. Frederico Graeff and Prof. Cesar Ades. Plenary lectures were delivered by international speakers Neil MacNaughton (University of Otago, Dunedin, New Zealand), Ian Stolerman (Institute of Psychiatry, King's College London, United Kingdom), and Fernando Cárdenas (Universidade de Los Andes, Bogota, Colombia). A meeting with this scope certainly helped cross-disciplinary research and its applications and shortened the distances between countries.

Psychology \& Neuroscience is an important partner of IBNeC that is committed to publishing high-quality papers in the area of behavioral and functional analyses of the brain (Landeira-Fernandez, Cruz, \& Ventura, 2008, 2010). The journal published proceedings from some of the main conferences at the meeting. It has been a great pleasure for us to serve as Guest Editors for this Special Issue. The following articles well reflect the wide variety of issues addressed during this exciting scientific event. The Second Annual Meeting of the IBNeC will be held in Recife, the capital of the Federal State of Pernambuco, Brazil, on October 13-15, 2011. We expect that the number of participants from Latin America and throughout Brazil will increase. If you have not yet become a member of $\mathrm{IBNeC}$, then you are cordially invited to join through the website (http://www.ibnec.org). 


\section{References}

Brandão, M.L. (2010). The first forum on the neurobiology of stress (editorial). Psychology \& Neuroscience, 3, 1.

Landeira-Fernandez, J., Cruz, A.P.M., \& Ventura, D.F. (2008)
Psychology \& Neuroscience: the birth of a new journal (editorial) Psychology \& Neuroscience, 1, 1-2.

Landeira-Fernandez, J., Cruz, A.P.M., \& Ventura, D.F. (2010). Psychology \& Neuroscience increases its visibility through database indexing (editorial). Psychology \& Neuroscience, 3, 133-134. 